DOSSIÊ "História e literatura"

\title{
Que Brasil existe? Estrangeiros na literatura brasileira
}

\author{
Stefania Chiarelli \\ Professora Adjunta do Instituto de Letras - Universidade Federal Fluminense (UFF) \\ stefania.techima@uol.com.br
}

Recebido em 18/06/2016. Aprovado em 02/09/2016.

Como citar este artigo: Chiarelli, S. "Que Brasil existe? Estrangeiros na literatura brasileira". Intelligere, Revista de História Intelectual, São Paulo, v. 2, n 2 [3], p. 40-48. 2016. ISSN 2447-9020. Disponível em http://revistas.usp.br/revistaintelligere>. Acesso em dd/mm/aaaa.

Resumo: $\mathrm{O}$ artigo traça breve panorama de autores que tematizam a imigração na literatura brasileira. Judeus, árabes, japoneses, italianos, alemães e afrodescendentes surgem como vozes dissonantes na teia discursiva da nação. Estabelecendo aproximações e contrastes, o texto busca pensar a relevância do enfoque dessas narrativas, que apresentam ângulo específico sobre a identidade nacional.

Palavras-chave: literatura brasileira; alteridade; memória; imigração.

\section{Which Brazil exists? Foreigners in Brazilian literature}

Abstract: This article outlines a brief panorama of authors that have the immigration inside Brazilian literature as a theme. Jews, Arabs, Japanese, Italians, Germans and Afro-descendants arise as dissonant voices in the nation's discursive web. Establishing approximations and contrasts, the text seeks to think the relevancy of these narratives' focus, which present specific angles on national identity.

Keywords: Brazilian literature; alterity; memory; immigration. 
"Você era um estranho e o Brasil o acolheu". A inscrição em vários idiomas aparecia já no cais da Hospedaria da Ilha das Flores, resumindo o discurso oficial do Estado brasileiro para aqueles que chegavam ao país. ${ }^{1}$ Mais de cem anos se passaram, muitos fizeram a América; outros nem tanto. Hoje - tempo de dramáticos questionamentos identitários, de fronteiras rígidas a separar o "eu" e o "outro", em que nacionalismos exacerbados problematizam a noção de alteridade - vale a pena se deter sobre escolhas lexicais, que nada tem de ingênuas. O endereçamento a um suposto "você" aproxima o viajante, sem, no entanto, deixar de lembrá-lo de sua estranheza/estrangeiridade. Tal condição aparentemente ficará circunscrita a um passado, tempo a ser soterrado na memória daquele que empreende jornada iniciática em novo lugar. Arrematando, o Brasil como pátria a redimir trajetórias extraviadas. Acolher, abrigar, proteger: o gesto redentor e generoso, mas também um alerta para o fato de que quem recebe ajuda se torna sempre um pouco devedor. Entre favor e generosidade, estranheza e familiaridade, estão os protagonistas destas histórias. Estrangeiros, imigrantes: agradeçam. O passado termina no cais, e o futuro se chama Brasil. Será?

Drummond, nos emblemáticos versos de "Hino Nacional", afirma que nenhum Brasil existe. É possível partir da provocação do poeta - "e acaso existirão os brasileiros? ” - e ainda uma vez indagar a respeito da identidade nacional. Como lembra Stuart Hall, ${ }^{2}$ ela nada tem de estável ou homogênea: uma vez que a identidade não existe como artefato natural, ela deve ser imaginada, de acordo com a conhecida formulação de Benedict Anderson. A imagem de paraíso racial, onde as três etnias originais se congraçam em harmonia, constitui uma espécie de discurso de fundação do caráter nacional. Mas é certo que nesse emaranhado identitário entram outros e complexos ingredientes. Tensões, preconceitos e disputas fazem parte do nó forjado para construir os relatos da nação.

Vale, portanto, pensar como a arte tenta responder a tais questões. Mais especificamente, como a literatura brasileira busca plasmar essa condição. Certas narrativas nos lembram da importância de se evitar a armadilha de uma perspectiva essencialista da identidade brasileira, apoiada em imagem pouco plural: elas auxiliam a desnaturalizar o mito edênico, ao insistir no fato de que não é possível apagar as marcas da violência na realidade do imigrante. A ausência de um projeto homogêneo de nação apontada nos versos de Drummond é problematizada inúmeras vezes em nossa prosa de ficção, que aponta a persistência de desigualdades maquiadas sob o discurso da tolerância. A partir dessa interrogação a respeito dos moldes identitários nacionais é possível pensar que diversos escritores contribuem, por meio de seus escritos, para problematizar a ideia de unidade e da pretensa cordialidade da sociedade brasileira.

Compreendendo o estrangeiro como figura recorrente da modernidade, e no lugar daquele que opera um contínuo trabalho de deslocamento, é possível indagar como essa figura surge nas narrativas de autores brasileiros para interrogar um discurso rígido a respeito da nação e da identidade como algo fechado. Ao analisar formas de representação do imigrante na literatura brasileira, de maneira geral duas tendências podem ser constatadas: de um lado, observa-se o predomínio da perspectiva histórica, em obras que recompõem trechos da colonização, como o clássico Canaã, de Graça Aranha (1902), história dos imigrantes alemães Milkau e Lentz, em uma pequena cidade do Espírito Santo, onde enfrentam dificuldades de adaptação à nova terra. Documento social, a obra mostra o confronto entre visões do mundo antagônicas e a violência do preconceito racial, assim como A ferro e fogo - tempo de solidão (1972), de Josué Guimarães. São relatos que dão conta das agruras da vida colonial, narrando a epopéia dos primeiros imigrantes

${ }^{1}$ Primeira instituição oficial para recepção de imigrantes criada pelo governo imperial, funcionou de 1883 até 1966 em São Gonçalo (RJ) e recebeu milhares de indivíduos de diversas etnias. Como se sabe, a abolição da escravatura e a política de branqueamento pautavam as ações daquele momento.

${ }^{2}$ Stuart Hall, A identidade cultural na pós-modernidade (Rio de Janeiro: DP\&A, 1999), 34. 
para iniciar uma nova vida em terra estranha. Identificam-se com a dicção grandiosa, apropriada para expor em minúcias a jornada empreendida pelos estrangeiros no país. O centro do interesse vai residir nos feitos extraordinários e na resistência dos imigrantes e sua luta pelo espaço e pela terra. Tal forma de lidar com a experiência da imigração opera na clave do épico, onde se fazem presentes personagens heroicos, protagonizando histórias de feitos extraordinários, aventuras e conquistas. Lidam com uma tradição e com o desejo de recuperá-la via narrativa.

Em outra perspectiva, surgem narrativas que focalizam aspectos do âmbito privado da vida do imigrante, focalizando quadro íntimo da vida de personagens marcados pela diferença cultural. Ao invés da visada coletiva, encontra-se uma história pessoal da imigração, como se pode averiguar em Contos do imigrante (1956), de Samuel Rawet, Relato de um certo Oriente (1989), de Milton Hatoum e Amrik, de Ana Miranda (1997) e O Bruxo do Contestado (1996), de Godofredo de Oliveira Neto, para ficar em apenas alguns exemplos. Esta é a tônica geral dessas obras. Trata-se de conquistas no âmbito do cotidiano, da família, da religião em um país periférico repleto de assimetrias. Indivíduos pertencentes a uma tradição dilacerada, impossível de ser recomposta, porque irremediavelmente perdida, os personagens vão percorrendo, na possibilidade da narrativa, espaços íntimos, pequenos dramas, em cotidianos que espelham a vivência do estrangeiro procurando se equilibrar nessa tênue linha entre culturas e linguagens distintas. Não há heróis, pelo menos não aqueles nos antigos moldes: seus feitos são no sentido de operar os códigos de outra cultura a contento.

Enquanto autores como Alcântara Machado em Brás, Bexiga e Barra Funda (1927) se detêm no tom de crônica de seus contos, registrando de modo bem-humorado o novo personagem italiano na cidade grande, outros, a exemplo de Samuel Rawet, buscam sondar o imigrante no aspecto da (não) adaptação do recém-chegado, caso de Contos do imigrante. Já Moacyr Scliar relata em suas obras maneiras pelas quais o imigrante judeu vai se adaptar à sociedade brasileira, algumas vezes sendo assimilado, outras, alterando significativamente a paisagem a seu redor, como em $A$ majestade do Xingu (1997). Autores como Ana Miranda, Salim Miguel e Milton Hatoum centram seu interesse no âmbito das relações familiares do imigrante libanês, no cotidiano de famílias que trazem marcas da cultura oriental. Por outro lado, Vianna Moog e Godofredo de Oliveira Neto oferecem perspectiva a respeito da adaptação do imigrante alemão no Brasil.

Vale ressaltar que a maneira de cada autor lidar com a questão da imigração é indissociável de sua própria trajetória pessoal: daqueles aqui referidos, Samuel Rawet e Salim Miguel vivenciaram diretamente a experiência da imigração. Os demais tiveram contato com o tema sobretudo por meio de relatos da geração que lhes precedeu e da própria comunidade em que se inseriram. ${ }^{3}$

Caso específico concerne o romance afro-brasileiro e os protagonistas dessas histórias. Vindos de forma forçada para o país, parecem sequer alcançar o status de imigrantes, o que sinaliza mais uma forma de negar a situação dramática de violência encerrada na escravidão. Língua, cultura e práticas cotidianas dos negros de diversos países da África serão fundamentais referências para a cultura brasileira e alteram significativamente nosso conceito de nação. Ainda que não seja possível neste espaço detalhar mais profundamente tal processo, vale ressaltar nesse quesito as obras de Conceição Evaristo e Ana Maria Gonçalves. Da primeira, destaque para Ponciá Vicêncio (2003), narrativa memorialística que traz como protagonista uma descendente de escravos africanos, e narra um percurso pontuado por perdas materiais, culturais e afetivas:

\footnotetext{
3 O caso de Alcântara Machado é ainda mais específico, pelo fato de o autor não ser um imigrante propriamente dito e tampouco pertencer à classe social que pretende representar.
} 
Bom mesmo que os filhos tivessem nascido mortos, pois assim se livrariam de viver uma mesma vida. De que valeria o padecimento de todos aqueles que ficaram para trás? De que adiantara a coragem de muitos em escolher a fuga, de viverem o ideal quilombola? De que valera o desespero de Vô Vicêncio? (...) A vida escrava continuava até os dias de hoje. Sim, ela era escrava também. Escrava de uma condição de vida que se repetia. ${ }^{4}$

Já Um defeito de cor (2006), de Ana Maria Gonçalves, narra em primeira pessoa a trajetória de Kehinde e seu deslocamento forçado da África ainda criança. Transitando por diversos lugares no Brasil, anos depois retorna ao continente africano, tematizando a situação dos chamados retornados. A autora cria uma narrativa cuja protagonista pode ter sido Luiza Mahin, líder feminista na Revolta dos Malê, ou Luiza Gama, mãe do poeta Luiz Gama, a quem se dirige a narradora.

\section{A Itália no Brasil}

Mesclando memória e ficção, Anarquistas, graças a Deus (1979), de Zélia Gattai, registra o cotidiano da família Gattai na São Paulo do início do século. Formada por pequenos episódios, a obra evoca de forma despretensiosa a vinda dos imigrantes italianos para o Brasil, em trechos que fazem referência à casa, aos amigos, ao bairro, à família e também às dificuldades de adaptação. Em Città di Roma (2000), a autora retoma o projeto literário iniciado com a obra anterior, centrando o enfoque do romance na viagem empreendida por seus familiares italianos a bordo do navio homônimo, bem como a chegada à cidade de São Paulo.

O tema foi também explorado por José Clemente Pozenato no romance O quatrilho (1985), ambientado na serra gaúcha no princípio do século. O título refere-se ao jogo de cartas de origem italiana, que serve como metáfora para a troca de casais que acontece no romance. Em Cocanha (2000), o autor volta a abordar a temática da imigração, percorrendo os primeiros anos da aventura colonial. ${ }^{5}$

Sem pretender esgotar o elenco, vale lembrar o autor mineiro Luiz Ruffato, que no projeto Inferno provisório, composto de cinco volumes, se propõe a ficcionalizar a história da classe operária no Brasil desde meados do século XX, e aborda a imigração italiana no Brasil, a exemplo do romance Mamma, son tanto felice (2005).

\section{A experiência da imigração judaica}

Quase trinta anos depois da publicação de Brás, Bexiga e Barra Funda, Samuel Rawet aprofundou o tema do estrangeiro de forma radical. O autor publicou Contos do imigrante aos 27 anos, inaugurando nas letras brasileiras o tema da literatura de imigração judaica. O caráter de isolamento da condição do imigrante adquire máxima importância, aprofundando a temática antes referida nas obras de autores como Mário de Andrade e Alcântara Machado. Para Rawet, o judaísmo é condição que trouxe inquietações e conflitos, uma vez que passa, a partir de determinado momento, a se autodenominar um "anti-judeu". A literatura daí resultante traz em si uma espécie de grito de alerta a respeito da intolerância, do estranhamento e da exclusão. A partir de sua experiência pessoal, o autor foi capaz de tratar o tema da imigração de maneira pungente, pois alude a um estado de incomunicabilidade passível de ser vivido por qualquer indivíduo.

\footnotetext{
${ }^{4}$ Conceição Evaristo, Ponciá Vicêncio (Belo Horizonte: Mazza Edições, 2003), 83-84.

5 Diferentemente do imigrante da cidade grande retratado por Alcântara Machado, numa galeria de tipos que engloba costureiras, alfaiates, operários da metrópole que inicia a se modernizar, os indivíduos apresentados por Pozenato são aqueles que se dirigiram ao interior do país, mais precisamente às pequenas propriedades do sul do Brasil. Os chamados colonos, por serem membros do grupo formado por indivíduos que cultivariam a terra estranha, ou seja, as colônias italiana e alemã - pretendiam viver da colheita e do plantio da terra.
} 
Autor que terá constante preocupação com a mesma temática é Moacyr Scliar. Dentre os inúmeros romances de Scliar, um deles realiza o cruzamento de duas importantes facetas da vida do autor, a literatura e a medicina. A majestade do Xingu relata a trajetória de dois jovens judeus russos emigrados no mesmo navio para o Brasil: o primeiro, Noel Nutels, médico que se dedicou à causa dos índios na região do Xingu - sanitarista que de fato viveu no país desde a década de 1920. O segundo, proprietário de uma lojinha no bairro do Bom Retiro, na cidade de São Paulo. Apesar do contato superficial travado entre ambos ainda meninos durante a viagem marítima, enorme admiração passa a existir por parte do futuro comerciante, que dedica sua vida à acompanhar, ainda que à distância, a trajetória de Nutels no Brasil. Toda a trama é narrada a partir da UTI de um hospital onde o narrador se encontra internado à beira da morte.

O mar, o porto e o navio são elementos altamente significativos no imaginário daqueles que partiram sem saber quando e se retornariam. É frequente a imagem desse tipo de embarcação nas narrativas brasileiras que tematizam a imigração. Já nos navios entulhados em que viajam começa a romper-se a intimidade familiar dos imigrantes pobres. Sobre o assunto, afirma Boris Fausto:

$\mathrm{Na}$ época das grandes migrações, a viagem transatlântica marítima constitui, como se sabe, o veículo por excelência dos deslocamentos; ela é para o imigrante um momento que marca sua vida. A partida assinala o encerramento de uma parte da existência ou quase sempre o abandono da pátria - a exceção maior sendo representada pelos judeus -, à qual muitas vezes se deseja retornar, sem que se tenha certeza da possibilidade do retorno. No outro pólo, a expectativa da chegada encerra esperanças, temores, incertezas. ${ }^{6}$

Em contraponto ao desconforto e às privações da travessia, povoam a imaginação dos imigrantes diversas expectativas em relação ao país de chegada: essas fantasias começavam a se formar ainda na Europa, no momento em que eram abordados por agentes encarregados de cooptar indivíduos dispostos a emigrar. Companhias de colonização agrícola anunciavam por panfletos a possibilidade de iniciar uma vida nova, e ofereciam terra, ferramentas agrícolas, gado, semente e o apoio necessário. Na propaganda apresentada, era recorrente a imagem do Brasil como terra de maravilhas e futuro promissor. A chegada de navio, de certa forma, corroborava essa visão do paraíso, pois os estrangeiros se deparavam pela primeira vez com um cenário exuberante que correspondia àquele alardeado pelos agentes.

Eu estava no Brasil, e o que via? Via as cores do Brasil. Deus, que cores. Que verdes. Que amarelos. Que encarnados. Que azuis. A Rússia era a terra do cinza, o cinza dos longos invernos, o cinza das casas; um cinza que correspondia à nossa paisagem interior. Mas o que eu tinha diante de mim era uma orgia de cores, uma profusa, esfuziante aquarela que chegava a me deixar tonto - como tonto me deixava a multidão que ali estava (...) Ana batia palmas, encantada, meus pais sorriam. Começávamos a gostar do Brasil. $^{7}$

Como desdobramento das distintas visões dos autores a respeito da imigração, seus textos trazem marcas bastante evidentes do modo como cada um encarou a experiência: enquanto Rawet presumia a impossibilidade da compreensão do outro em sua irreconciliável diferença, Scliar mantém visão otimista a respeito do tema. Em seus personagens prepondera olhar marcado pela possibilidade de inaugurar nova vida em terra estranha, ainda que sejam indivíduos marcados pela

\footnotetext{
${ }^{6}$ Bóris Fausto, "Imigração: cortes e continuidades” em Lilia M. Schwarcz (org.), História da vida privada no Brasil, vol. 4 (São Paulo: Companhia das Letras, 1998), 13-61.

${ }^{7}$ Moacyr Scliar, A majestade do Xingu (São Paulo: Companhia das Letras, 1997), 25.
} 
coexistência de duas metades (judeu-brasileiros, reunindo em si diferentes identificações, como a imagem evocada pelo ser mitológico de $O$ centauro no jardim, romance publicado em 1980).

\section{Ecos do Japão no Brasil}

Há mais de cem anos se deu o início da entrada de imigrantes japoneses no Brasil. Indivíduos dessa etnia estão presentes no país há décadas, e ainda assim é escassa sua representação na literatura brasileira. Oswald de Andrade, com Marco zero - romance publicado em dois volumes, A revolução melancólica (1943) e Chão (1946) -, incorpora personagens japoneses ao traçar um panorama da sociedade paulista nos anos 1930. Nestas e em outras narrativas, trata-se de uma fala que mimetiza a dificuldade do imigrante de dominar a nova língua. A esse respeito, vale lembrar o personagem Tanaka, criado japonês da família Sousa Costa, de Amar, verbo intransitivo (1928), de Mário de Andrade. A discussão sobre nacionalidade comparece no diálogo entre Fräulein, a preceptora alemã, e o serviçal. Denominados como "tigres" que se arranham em contínua rivalidade de dia, à noite dialogam comovidamente, contando mágoas passadas, a infância longínqua - descritos pelo narrador como almas desinfelizes exiladas.

Já o romance Nihonjin (2012), de Oscar Nakasato, aposta no resgate das vivências de deslocamento geográfico e cultural de imigrantes japoneses no Brasil. Hideo Inabata imigra de Kobe para São Paulo no princípio do século passado, cioso de sua nacionalidade e prestando culto ao Imperador. O embate entre visões de mundo e o dilaceramento das tradições darão o tom desse romance, narrado pela voz da terceira geração, cuja visão estabelece espécie de balanço geracional diante de expressivas mudanças e adaptações. Ainda no campo da prosa contemporânea, podemos destacar O sol se põe em São Paulo (2007), de Bernardo Carvalho, Rakushisha (2007), de Adriana Lisboa e O único final felizpara uma bistória de amor é um acidente (2010), de João Paulo Cuenca. Sob o signo da desterritorialização, a cultura japonesa surge na forma de personagens de origem nipônica ou no aspecto de uma determinada visão sobre o país.

\section{Vozes árabes}

A presença do imigrante árabe na literatura brasileira pode ser percebida em diversos romances de Jorge Amado, recebendo em geral tratamento mais próximo do exotismo e do estereótipo. O personagem Nacib, de Gabriela, cravo e canela (1958) faz parte dessa galeria.

Já o romance Lavoura Arcaica (1975), de Raduan Nassar, inaugura outra percepção a esse respeito, ainda que este não seja seu tema central. Além da temática, a elaboração textual, o tratamento das relações familiares, a trágica relação estabelecida entre as personagens fazem deste um romance ímpar na literatura brasileira. Apesar de não explicitada diretamente, a origem dos membros familiares é árabe, o que pode ser verificado na ocorrência dos nomes, a começar pela referência ao patriarca Iohána e as filhas Zuleika e Huda. A alusão constante ao avô, "velho imigrante", também faz presente a questão da imigração: "É na memória do avô que dormem nossas raízes"8 afirma o patriarca Iohaná, revelando em seu discurso permanente zelo pelos valores dos ancestrais. Imigrante com "sintaxe própria, dura e enrijecida pelo sol e pela chuva", ele encarna a geração de imigrantes que vem ainda jovem para o Brasil, depositário de uma cultura oriental que pauta suas ações. É a chamada geração do sotaque, pois carrega no modo de falar o português a sonoridade facilmente reconhecível de sua língua materna. Marcado pelo respeito aos valores antigos de seu povo, esse imigrante enfrenta maior dificuldade de adaptação, se comparado àquele da geração que a sucede, caso de seu filho André, já nascido no Brasil e narrador do romance.

\footnotetext{
${ }^{8}$ Raduan Nassar, Lavoura Arcaica (São Paulo, Livraria José Olympio Editora, 1975), 25.
} 
A narrativa de Nassar terá decisivo impacto na tessitura de Relato de um certo Oriente (1989), de Milton Hatoum, que narra a trajetória de uma família libanesa em Manaus, compondo, por meio da narrativa de diversas vozes familiares, um emocionante mosaico. Dialogando com matrizes memorialistas, o romance apresenta os conflitos e o desmantelamento de uma família matriarcal, através do olhar de seus descendentes:

Desde pequeno convivi com um idioma na escola e nas ruas da cidade, e com um outro na Parisiense. E às vezes tinha a impressão de viver vidas distintas. Sabia que tinha sido eleito o interlocutor número um entre os filhos de Emilie: por ter vindo ao mundo antes que os outros? Por encontrar-me ainda muito próximo às suas lembranças, ao seu mundo de figueiras e parreiras, dos carneiros, Junieh e Ebrin??

O autor retoma a temática em Dois irmãos (2000), em que os gêmeos Yaqub e Omar debatem-se durante toda a vida entre o amor e o ódio em meio a uma família libanesa, em narrativa novamente ambientada na cidade de Manaus.

Ana Miranda no romance Amrik (1997) aborda igualmente a questão da imigração árabe, narrando a trajetória da personagem Amina e do mascate Abrahão, que chegam à cidade de São Paulo no início do século XIX. A narrativa caracteriza-se por incorporar inúmeros vocábulos da língua de origem dos personagens, o que cria no leitor a sensação de frequentar um território muito próprio, dada a variedade lexical empregada. Nür na escuridão (1999), romance autobiográfico de Salim Miguel, é narrativa que igualmente aborda o deslocamento geográfico e cultural do imigrante libanês no Brasil. Com mais de trintas livros publicados, o autor veio aos três anos do Líbano com a família para o Brasil.

\section{Ideologia e preconceito: personagens germânicos}

Um rio imita o Reno (1939) aborda a temática da imigração germânica no Brasil ao estabelecer também o contraponto entre as culturas brasileira e alemã. Sob o pretexto de narrar a história de amor entre o amazonense Geraldo e Lore Wolff, jovem de família protestante, Viana Moog se detém em temas como a disseminação da propaganda nazista na comunidade alemã de uma cidade do sul do Brasil. Documenta, desta forma, aspectos controvertidos da sociedade brasileira, como o preconceito e a intolerância e estabelece minucioso desenho das práticas culturais entre os descendentes de alemães, que já não necessitavam firmar-se economicamente no país: contrariamente ao imigrante alemão descrito por Josué Guimarães em A ferro e fogo, estes sujeitos se encontram plenamente estabelecidos no Brasil. A luta pela estabilidade econômica tema onipresente no imaginário do estrangeiro - para estes cidadãos já foi cumprida.

Desde sua chegada, Geraldo vivencia o estranhamento ao se deparar com as indicações da cidade: "Apotheke, Schumacher, Backerei". O personagem surge como elemento estranho na germanizada Blumental, invertendo a perspectiva tradicional do imigrante como alvo do preconceito. É Geraldo o estrangeiro, indivíduo recebido com desconfiança em espaços dominados pelos germânicos:

Geraldo então atentou ainda mais para o quadro, retesando a atenção. Blumental dava-lhe a impressão de uma cidade do Reno extraviada em terra americana. Desde o gótico da igreja, até a dura austeridade das fachadas, tudo nela, à exceção do jardim, era grave, rígido, tedesco. (...) um tumulto, uma angústia interior agarrava-lhe as entranhas. Geraldo teve vontade de chorar. Sentia saudades do Brasil..$^{10}$

\footnotetext{
${ }^{9}$ Milton Hatoum. Relato de um certo Oriente (São Paulo: Companhia das Letras, 1989), 52

${ }^{10}$ Viana Moog, Um rio imita o Reno (Rio de Janeiro, José Olympio, 1987), 34, grifos meus.
} 
Heidelberg, Munique. O Reno. Referências germânicas transplantadas para os trópicos, mas um tanto fora do lugar, extraviadas. A referência a alguma coisa perdida no tempo e no espaço aponta para o desejo de re-encontrar o Brasil. Um Brasil que para Geraldo aparece distante, velado por uma aura nostálgica. Para o engenheiro vindo do Norte, o choque vai caracterizar a visão de tal cidade, uma vez que não reconhece aquele espaço como "brasileiro" e não se sente reconhecido como parte integrante daquela comunidade. Ali existe um rio - como tantos na região amazônica - mas ele ecoa o Reno, e esse arremedo diz muito dos habitantes desse cenário um tanto falsificado.

Bugre enamorado de deusa branca - uma das imagens utilizadas pelo autor para aludir ao modo como Geraldo se vê na condição de apaixonado - alude a uma situação de inferioridade introjetada, uma vez que o personagem sente-se angustiado ao imaginar que Lore despreza o caboclo de cabelos escorridos. Comparece a histórica relação entre o europeu e o colonizado, a antinomia entre uma presumida pureza e a inferioridade atribuída aos indígenas. Sentimento que Geraldo vivencia por meio das referidas saudades do Brasil, lugar de águas extraviadas, cujos rumos se perderam. O escritor procura, nos anos 1930, problematizar a alteridade e o choque de culturas, momento em que o índio e o imigrante - fortes ícones da representação da nação comparecem em situações antípodas.

Assim como se evidencia o transplante cultural e a inadequação de Geraldo a partir de sua configuração como leitor, o mesmo se dá em relação a Tecla, narradora de O Bruxo do Contestado (1996), de Godofredo de Oliveira Neto. A sedução provocada pelo universo dos livros propicia nas narrativas uma reflexão a respeito do desvendamento de novos territórios, demonstrando o estranhamento ou a familiaridade dos personagens com novas realidades. A ideia da leitura como viagem e a noção da viagem como leitura ficam nítidas na construção de personagens como Geraldo: o encanto pela filosofia nietzscheana predispõe a paixão por Lore, sereia que arrasta Geraldo até paisagens já visitadas em seu repertório de leituras. A identidade germânica também é problematizada no romance de Oliveira Neto. A ideologia nazista e a disseminação da propaganda entre brasileiros igualmente ocupa a trama da narrativa, que traz personagens em situação de inadequação e deslocamento.

Em mapeamento da literatura brasileira do século XXI, Flávio Carneiro sustenta que as diretrizes da literatura dos anos 1990 se pautam por um novo romance histórico, construído em grande parte sob o signo da reescritura. ${ }^{11} \mathrm{~A}$ partir da temática do estrangeiro, seria possível pensar esse romance à luz da reescrita da História. O laço entre escrita ficcional e discurso histórico é problematizado a partir do momento em que outras verdades e narrativas vem à tona, como postula Linda Hutcheon. Mais do que saber o que é o passado, a pergunta seria: o que podemos conhecer do passado hoje?

Recusando trabalhar com tipos ou sínteses históricas, tais narrativas dissertam muitas vezes sobre personagens marginalizados ou periféricos, como no caso dos imigrantes e dos sujeitos escravizados, conforme referido anteriormente. Romances como O Bruxo do Contestado instalam uma crise na historicidade, pois problematizam a noção de conhecimento historic. ${ }^{12}$ Elementos factuais - no caso, o movimento de cunho messiânico no sul do Brasil - são recriados por meio da narrativa ficcional. Essa mistura proposital entre ficção e história permite reescrever o passado na ficção e na história, sem a pretensão de ser conclusivo, afirma Hutcheon. ${ }^{13}$ Tematiza-se o messianismo no sul do país, mas são os Rünnel - Juta, Rosa e Gerd - os protagonistas dessa jornada. A utopia do retorno do Contestado mobiliza o personagem Gerd, assim como o sonho de

${ }^{11}$ Flávio Carneiro, Ficção brasileira do século XXI (Rio de Janeiro: Rocco, 2005), 14.

${ }^{12}$ Linda Hutcheon, Poética do pós-modernismo - bistória, teoria, ficção (Rio de Janeiro, Imago, 1990), 122.

${ }^{13}$ Idem, 147. 
realizar um balanço geracional mobiliza Tecla: "vou manter vivo o bruxo", ${ }^{14}$ sustenta a narradora, lembrando que essas serão as suas memórias. Relatar a trajetória do bruxo é também falar de si e de sonhos arruinados. O corpo de Gerd, o estrangeiro, não é encontrado no desenlace da narrativa, permanecendo como elipse, lacuna a ser preenchida pelo leitor.

O gesto de interrogar o imaginário de quem partiu se revela fundamental para o entendimento de tantos desses relatos. De modo geral, todos trazem sujeitos à margem de um ideal homogêneo de nação. Ler tais narrativas implica não somente realizar uma análise estética de textos literários que tematizam a alteridade, mas revela a intenção de pensar o compromisso político do crítico - aquele que deve assumir a responsabilidade pelos passados não ditos a assombrar o presente histórico, conforme assinala Homi Bhabha. ${ }^{15}$ Significa empreender, portanto, uma mirada movida pelo desejo de encontro referido pelo crítico indiano, recortando do heterogêneo conjunto da literatura brasileira episódios em que esses estrangeiros passam a protagonistas, ou a elementos centrais para a compreensão das narrativas. ${ }^{16}$

Revelar o presente a partir de uma determinada leitura do passado é necessário para compreender a cultura brasileira a partir de escritos que inúmeras vezes irão se ocupar de personagens excêntricos, fora da órbita do progresso e do discurso homogeneizante da nação. Imigrantes, deslocados, expatriados, sujeitos com sotaque, descendentes que aprendem o português de forma vacilante. Gringuinhos, crianças que balbuciam, gaguejam em uma língua que não sentem como sua. Indivíduos que se inserem na cultura brasileira de forma lateral, ambígua. Nenhum Brasil existe, e esses relatos nos lembram de que há múltiplas formas de imaginar quem são os brasileiros. Falar com esses estranhos, ouvi-los, tornar produtivas suas histórias é um gesto necessário e revelador. Olhar para tais narrativas é também uma forma de compreender a literatura brasileira em sua complexidade e variedade.

\footnotetext{
${ }^{14}$ Godofredo de Oliveira Neto, O Bruxo do Contestado (Rio de Janeiro: Record, 2012), 76.

${ }^{15}$ Homi Bhabha, O local da cultura. [Trad. Myriam Ávila, Eliana Reis e Gláucia Gonçalves] (Belo Horizonte: UFMG, 1998), 41.

${ }^{16}$ Distintas abordagens do tema encontram-se reunidas no volume Falando com estranhos - o estrangeiro e a literatura brasileira (Rio de Janeiro: 7Letras, 2016), organizado por Godofredo de Oliveira Neto e a autora.
} 